\title{
Protokol New Normal Order Pasca Pandemi Covid-19 dalam Pengembangan Kampoeng Boenga Grangsil Berbasis Masyarakat
}

\author{
Respati Wikantiyoso ${ }^{1}$, Diyah Sukanti Cahyaningsih², Aditya Galih Sulaksono ${ }^{3}$, Sri Widayati ${ }^{4}$ \\ ${ }^{1}$ Departemen Magister Arsitektur Program Pascasarjana, ²Departemen Akuntansi Fakultas Ekonomi dan Bisnis, \\ ${ }^{3}$ Departemen Sistem Informasi Fakultas Teknologi Informasi, ${ }^{4}$ Departemen Komunikasi Fakultas IImu Sosial dan IImu \\ Politik, Universitas Merdeka Malang. \\ Jl. Terusan Raya Dieng No.62-64 Malang, 65146, Indonesia
}

\section{ARTICLE INFO:}

Received: 2020-08-04 Revised: 2020-9-26 Accepted: $2020-10-22$

\section{Keywords:}

Community base tourism; COVID-19 protocol; New normal order

\section{ABSTRACT}

The tourism development sector in Indonesia is overgrowing. During the COVID-19 pandemic, it was the sector most affected economically. The COVID1-9 pandemic has changed the "normal" conditions in all life sectors, including tourism sector activities. The uncertainty over the end of the COVID-19 pandemic requires us to adapt to the new conditions, the new prerequisites (social and physical distancing), and the new order (physical, social, and health) preparing the new normal order protocol. The recovery of tourism sector activities must be aware of the emergence of new clusters in tourist destinations. The purpose of the discussion in this paper is to produce a new normal order protocol after the COVID-19 pandemic for the development of sustainable community-based rural tourism destinations. The efforts that prepare are the new normal order after COVID-19, by taking into account: (1) Mitigation of tourism "disasters" due to COVID-19; prevent new clusters in tourist villages/ villages (2) Compilation of health protocols for tourist destinations during the COVID-19 pandemic era; (3) Strengthening information on destination environmental health; (4) Strengthening the Destination Management Organization (DMO) especially for the management of the COVID-19 tourism village protocol; and (5) Increasing stakeholder participation towards a new normal order.

(c) 2020 Published by University of Merdeka Malang. This is an open access article distributed under the CC BY-SA 4.0 license (https://creativecommons.org/licenses/by-sa/4.0/)

How to cite: Wikantiyoso, R., Cahyaningsih, D. S., Sulaksono, A. G., \& Widayati, S. (2020). Protokol New Normal Order Pasca Pandemi Covid-19 dalam Pengembangan Kampoeng Boenga Grangsil Berbasis Masyarakat. Abdimas: Jurnal Pengabdian Masyarakat Universitas Merdeka Malang, 5(3), 181-192.

https://doi.org/10.26905/abdimas.v5i3.4803

\section{PENDAHULUAN}

Indonesia salah satu negara meratifikasi dan melaksanakan kerangka Tujuan Pembangunan Berkelanjutan atau Sustainable Development Goals (SDG's) untuk pencapaian hingga 2030. Paling tidak ada empat dari 17 SDG's yang terkait dengan pengembangan pariwisata pedesaan berbasis masyarakat (Wikantiyoso 
ABDIMAS: Jurnal Pengabdian Masyarakat Universitas Merdeka Malang

Volume 5, No 3, November 2020: 181-192

et al., 2019). SDG's yang ke-11 bertujuan untuk menjadikan kota dan permukiman yang inklusif, aman, tangguh, dan berkelanjutan. Hal ini dapat dimaknai bahwa pembangunan pariwisata perdesaan harus ditujukan untuk menjaga tanah dan ekosistem, pemberdayaan masyarakat, membangun masyarakat tangguh, lembaga dan kemitraan yang kuat untuk menciptakan komunitas yang berkelanjutan dan pengembangan pariwisata berkelanjutan (Wikantiyoso et al., 2019). Tantangan pengembangan pariwisata berkelanjutan adalah menemukan model atau pendekatan yang meningkatkan kesejahteraan sosial masyarakat dengan menggunakan sumber daya alam secara bijak untuk melindungi lingkungan sambil mempertimbangkan cadangan sumber daya yang tersedia untuk generasi sekarang dan yang akan datang (Shaw, 1993).

Pengembangan pariwisata pedesaan dimulai dengan menentukan karakteristik lokal wilayah tersebut dari sudut pandang sosial-budaya dan lingkungan (Amir et al., 2015; Hung \& Jan, 2019). Ini menyelidiki fitur-fitur potensial seperti makanan, budaya dan ritual keagamaan serta lingkungan. Ini dapat digolongkan sebagai aspek kreatif pariwisata pedesaan - menjadikan destinasi wisata unik dan menarik. Beberapa faktor mempengaruhi perkembangan desa wisata; yaitu keunikan lokasi, keterlibatan pelaku wisata utama (masyarakat lokal), pembiayaan kegiatan pariwisata serta peran memobilisasi partisipasi masyarakat dan keterlibatan di antara para pemangku kepentingan. Pengembangan pariwisata berbasis masyarakat meningkatkan jumlah fasilitas, taman, atraksi budaya, pengalaman visual rekreasi dan memberi manfaat bagi kualitas hidup masyarakat serta memberi mereka rasa bangga ketika budaya mereka diterima dan dihormati oleh wisatawan (Hung \& Jan, 2019).

Aspek kreatif pengembangan desa tematik atau kampung pariwisata yang saat ini sedang dilaksanakan oleh masyarakat, termasuk masyarakat Dusun Grangsil desa Ahmbangan ini. POKDARWIS (Kelompok Kesadaran Pariwisata) mengembangkan tujuan wisata di KBG (Kampoeng Bunga Grangsil). Grangsil berada di Desa Jambangan, Kecamatan Dampit, Kabupaten Malang; di lereng berbukit dan indah Gunung Semeru. Tanah subur dan sumber air yang tersedia di Gunung Semeru ideal untuk menghasilkan komoditas pertanian, terutama tanaman hias dan bunga. Komunitas pertanian Grangsil memiliki etos kerja, kerja sama, dan moral yang relatif baik.

Sebelum pandemi COVID 19, industri pariwisata merupakan sektor yang berkembang pesat yang tidak hanya berkontribusi pada peningkatan ekonomi tetapi juga menciptakan peluang kerja (Begum et al., 2014). Akan tetapi, pada masa pandemi COVID-19 menjadi sektor yang paling terdampak secara ekonomi. Pandemi COVID1-9 telah mengubah kondisi "kenormalan" di semua sektor kehidupan termasuk pada kegiatan sektor wisata. Pemerintah Indonesia memberikan perhatian serius pada pembangunan pedesaan yang adil melalui Kebijakan Dana Desa (Mulyani, 2017) di mana, hampir semua masyarakat pedesaan didorong untuk mempromosikan pariwisata dengan mengembangkan rencana dan desain sesuai dengan potensi masing-masing daerah. Pengembangan masyarakat berkelanjutan yang sukses adalah indikator keberhasilan pembangunan pedesaan. Kunci menuju komunitas berkelanjutan yang sukses membutuhkan keterlibatan komunitasnya di setiap tahap proses pembangunan. Dalam konteks pengembangan pariwisata berbasis masyarakat, keterlibatan masyarakat adalah fokus utama.

Merebaknya pandemi COVID-19 ini menjadikan permasalahan pengembangan Mitra PPDM (Destinasi Wisata Kampoeng Boenga Grangsil) menjadi semakin kompleks. Ada empat permasalahan yang dihadapi Mitra PPDM yang akan disolusikan pada pelaksanaan pengabdian, yakni: (1) Permasalahan utama yang menjadi tantangan terberat dalam pengembangan KBG saat ini adalah permasalahan penyebaran pandemi COVID-19; (2) Permasalahan pengembangan fisik obyek wisata; (3) Permasalahan pemanfaatan teknologi IT dan TTG; serta (4) Permasalahan pemberdayaan masyarakat. 


\section{Protokol New Normal Order Pasca Pandemi Covid-19 dalam Pengembangan Kampoeng Boenga Grangsil...}

Respati Wikantiyoso, Diyah Sukanti Cahyaningsih, Aditya Galih Sulaksono, Sri Widayati

Luaran yang akan dihasilkan berupa dihasilkannya beberapa protokol COVID-19 untuk mengkawal pemulihan aktivitas wisatawan di Kampoeng Boenga Grangsil dalam rangkan menyongsong new normal order era menuju transisi kenormalan baru. Pemulihan aktivitas sektor wisata harus mewaspadai munculnya cluster baru pada destinasi wisata, yang disebabkan terabaikannya protokol kesehatan. Kunci utama pemulihan aktivitas wisata adalah harus disiplin menerapkan protokol kesehatan yang rigid. Tujuan pembahasan dalam makalah ini adalah menghasilkan protokol new normal order pasca pandemi COVID19 untuk pengembangan destinasi wisata pedesaan berbasis komunitas berkelanjutan.

Ketidakpastian berakhirnya pandemi COVID-19, mengharuskan kita untuk mampu beradaptasi dengan kondisi baru, prasyarat baru (social and physical distancing), tatanan baru (fisik, sosial dan kesehatan), dengan mempersiapkan protokol new normal order. Pemulihan aktivitas sektor wisata harus mewaspadai munculnya cluster baru pada destinasi wisata, yang disebabkan terabaikannya protokol kesehatan. Pandemik COVID-19 ini menjadi permasalahan prioritas dalam pelaksanaan PPDM tahun 2020 ini. Beberapa pertanyaan yang krusial dalam pengembangan pariwisata berbasis masyarakat di era pandemi COVID-10 diantaranya; (1) Apa peran manajemen destinasi wisata dalam pengembangan KBG sebagai upaya untuk meningkatkan ketahanan masyarakat (community resilience)?; (2) Bagaimanakah mempersiapkan kondisi KBG sehingga siap menjalankan pemulihan bisnis dengan tatanan baru (protokol new normal) pada masa transisi pandemi COVID-19; (3) Protokol new normal order pasca pandemi COVID-19 apa sajakah yang diperlukan dalam pengembangan destinasi wisata pedesaan berbasis komunitas.

Keberhasilan pengembangan desa mitra tahun kedua (2020), melalui pengembangan KBG Desa Jambangan akan meningkatkan daya saing wilayah pedesaan khususnya Desa Jambangan dengan icon Kampoeng Boenga Grangsil dan dapat menjadi model pembangunan berbasis komunitas (Wikantiyoso et al., 2019; WWF-Indonesia, 2009) dalam pengembangan destinasi wisata. Permasalahan yang ditemukenali sebagaimana telah diuraikan, harus ditetapkan skala prioritas dalam penanganannya. Keempat permasalahan tersebut diselesaikan secara simultan dan berkelanjutan, dalam kurun waktu 2 tahun ke depan diharapkan akan dapat mewujudkan destinasi wisata yang mendiri, serta mampu menjadi generator ekonomi Desa Jambangan khususnya di Dusun Grangsil.

Pada pelaksanaan PPDM 2020 ini diharapkan akan menghasilkan protokol new normal order pasca pandemi COVID-19 untuk pengembangan destinasi wisata pedesaan berbasis komunitas berkelanjutan. Berkaitan dengan hal tersebut, harus ada upaya kongkrit mempersiapkan tatanan normal baru pasca COVID-19, yang memperhatikan: (1) Upaya mitigasi "bencana" pariwisata karena COVID-19; mencegah munculnya kluster baru di Kampoeng/desa wisata; (2) Penyusunan protokol kesehatan pada destinasi wisata pada era pandemi COVID-19; (3) Penguatan informasi terhadap kebersihan dan kesehatan lingkungan destinasi; (4) Penguatan Destination Management Organization (Aleksandrov \& Kilimperov, 2018; Caldito et al., n.d.; Siri \& Chantraprayoon, 2017) terutama terhadap pengelolaan Desa Wisata terkait Protokol COVID-19; dan (5) Peningkatan partisipasi stakeholders dalam upaya menuju tatanan kenormalan baru menjadi penting dilakukan dalam rangka meningkatkan kesadaran baru.

\section{METODE}

Pelaksanaan Pengabdian ini menggunakan metode pendekatan partisipatif (Astuti, 2001; Andriany et al., 2015), dimana pengabdi ikut serta (partisipatif) didalam proses perencanaan pemecahan masalah 
ABDIMAS: Jurnal Pengabdian Masyarakat Universitas Merdeka Malang

Volume 5, No 3, November 2020: 181-192

dalam mencapai tujuan bersama. Pelaksanaan pendampingan partisipatif ini dilakukan melalui proses pendampingan in-situ dan pendampingan ex-situ. Pendampingan dilaksanakan dengan membimbing dan memotivasi para pemangku kepentingan untuk berpartisipasi dalam gagasan curah pendapat, memberdayakan diri mereka sendiri, kelompok, organisasi dan masyarakat serta mengembangkan kebijakan perencanaan bisnis pariwisata yang akan dilaksanakan secara mandiri di masa depan untuk mewujudkan resilience community-based tourism development.

Tahapan pelaksanaan pengabdian, khusunya dalam mengatasi permasalahan dampak pandemi COVID-19 ini dapat digambarkan dalam diagram kerangka pengabdian (Gambar1), ketiga tahap tersebut adalah: (1) Identifikasi masalah, pemecahan masalah, dan identifikasi peluang untuk tumbuh berdasarkan kebutuhan dan potensi masyarakat Grangsil, khususnya pada masa transisi new normal pandemi COVID19; (2) Brainstorming dan mengidentifikasi peluang dan hambatan dalam mengembangkan peluang yang ada pada kondisi pandemi COVID-19; membantu dan memperkuat organisasi dan institusi, melalui pembentukan tim siaga COVID-19; dan meningkatkan pemahaman dan ketahanan menghadapi Pandemi dalam kerangka mewujudkan resilience community-based tourism development. dan (3) Menganalisis dan mensintesis data yang dikumpulkan melalui penyamaan persepsi di antara para pemangku kepentingan untuk mengembangkan model protokol new normal order pasca pandemi COVID-19 untuk pengembangan destinasi wisata pedesaan berbasis komunitas berkelanjutan.

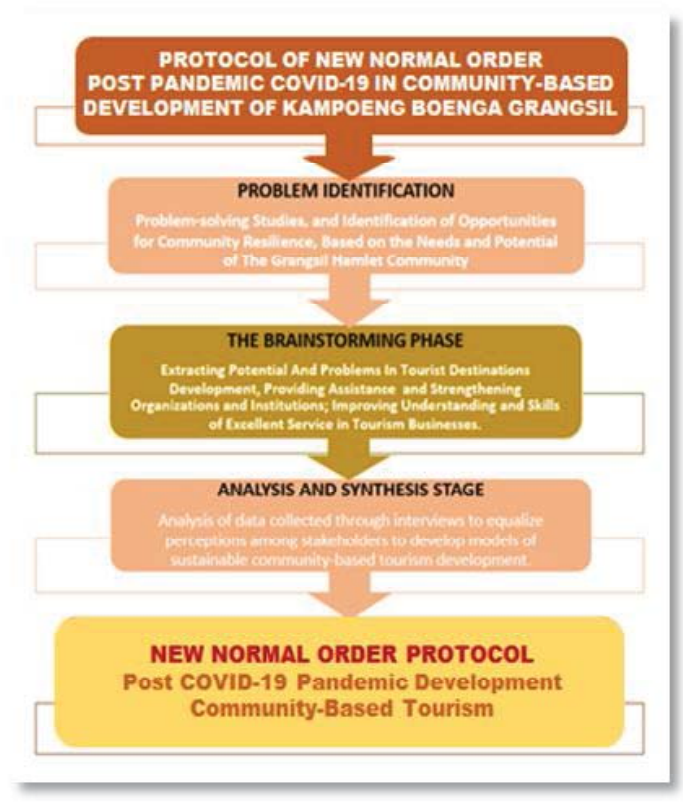

Gambar 1. Kerangka pembahasan

\section{HASIL DAN PEMBAHASAN}

Pembahasan pada makalah ini bertujuan untuk menghasilkan solusi protokol new normal order pasca pandemi COVID-19 untuk pengembangan destinasi wisata pedesaan berbasis komunitas berkelanjutan. Solusi tersebut merupakan pemecahan terhadap permasalahan utama pelaksanaan pengabdian PPDM tahun 2020, yakni permasalahan penyebaran pandemi COVID-19 yang secara langsung berdampak 
signifikan terhadap pengembangan bisnis pariwisata. Ada tiga (3) pertanyaan yang krusial dalam pengembangan pariwisata berbasis masyarakat di era pandemi COVID-10, yakni: (1) Apa peran manajemen destinasi wisata dalam pengembangan KBG sebagai upaya untuk meningkatkan ketahanan masyarakat (community resilience)?; (2) Bagaimanakah mempersiapkan kondisi KBG sehingga siap menjalankan pemulihan bisnis dengan tatanan baru (new normal protocol) pada masa transisi pandemi COVID-19?; dan (3) Protokol new normal order pasca pandemi COVID-19 apa sajakah yang diperlukan dalam pengembangan destinasi wisata pedesaan berbasis komunitas?

Permasalahan penyebaran pandemi COVID-19 menjadi tantangan terberat dalam pengembangan KBG. Sehingga praktis beberapa kegiatan pengembangan dilakukan pengalihan (penggantian program) untuk memfokuskan pada solusi permasalahan ini. Hal ini dilakukan sesuai dengan kebijakan Direktorat Riset dan Pengabdian Masyarakat Kementrian Ristek/BRIN, untuk melaksanakan model pengabdian masyarakat dalam situasi COVID-19 secara online. Kebijakan ini merupakan respon akan pentingnya penanganan, khususnya pencegahan penyebaran pandemi COVID-19. Berkaitan dengan hal ini maka, Tim PPDM melakukan beberapa langkah yakni peningkatan pengetahuan, keahlian, serta kemampuan kelembagaan KBG dalam mewujudkan ketahanan komunitas (resilience community) sebagai hasil proses pembangunan yang berkelanjutan. Upaya ini dilakukan untuk menjawab pertanyaan tentang peran manajemen destinasi wisata dalam meningkatkan ketahanan masyarakat. Pembahasan tentang pembangunan masyarakat yang berkelanjutan, tujuan akhirnya adalah pencapaian kondisi resilience community (Adger, 2000; CARRI, 2014; Sharifi, 2016; Wikantiyoso et al., 2019). Pengembangan pariwisata berkelanjutan tidak hanya dalam hal pembangunan berkelanjutan tetapi juga bagaimana bisnis pariwisata dapat berkelanjutan, termasuk merespon tantangan pandemi COVID 19. Resilience community merupakan kemampuan untuk mengantisipasi risiko, membatasi dampak dan pulih dengan cepat melalui kelangsungan hidup, kemampuan beradaptasi, evolusi dan pertumbuhan dalam menghadapi perubahan yang cepat (CARRI, 2014). Pembangunan yang berpusat pada manusia (human-center development) diperlukan untuk menyelaraskan pembangunan melalui upaya pemberdayaan masyarakat, dan peran sumber daya masyarakat yang ada (Pamatang et al., 2013).

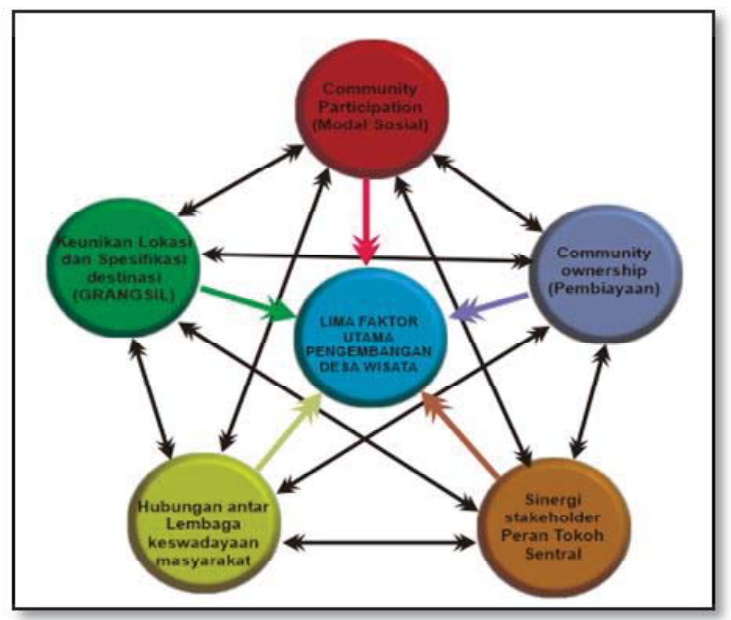

Gambar 2. Sinergi pengembangan destinasi wisata perdesaan

Keberhasilan pencapaian ketahanan masyarakat, dapat diakselerasi melalui peningkatan kemampuan, keterampilan, dan pengetahuan pengelolaan sumberdaya lokalnya, dilakukan melalui upaya pendampingan 
ABDIMAS: Jurnal Pengabdian Masyarakat Universitas Merdeka Malang Volume 5, No 3, November 2020: 181-192

untuk pemberdayaan potensi lokal. Sinergi antar pelaku atau stakeholders pengembangan destinasi wisata menjadi sangat penting untuk dilakukan. Hal ini penting untuk cipta kondisi yang kondusif dalam meningkatkan peran serta dalam kontribusi sumberdaya yang dimiliki. Setidaknya ada lima (5) apek utama yang harus diperhatikan dalam pengembangan pariwisata perdesaan (Mujanah et al., 2016; Sudirah, 2015) adalah: (1) Community participation; modal sosial yang sangat penting bagi pengembangan wisata perdesaan; (2) Community ownership; partisipasi yang tinggi dapat meningkatkan "rasa memiliki" masyarakat yang penting bagi upaya marketing dari dalam; (3) Stakeholders synergy, pentingnya tokoh sentral sebagai motivator, penggerak pemberdayaan; (4) Institutional cooperation; Hubungan kerjasama antar lembaga/ institusi; dan (5) Local uniqueness and linkage; Keunikan destinasi, dan keterkaitan dengan destinasi wisata lainnya. Sinergi kelima faktor tersebut dapat mendorong terjadinya cipta kondisi resilience destination management, yang sangat diperlukan untuk mendorong penguatan kelembagaan dan tatakelola destinasi wisata.

Mempersiapkan tim dan mitra (Tim Kampoeng Boenga Grangsil) untuk menangani secara serius terhadap permasalahan tatantangan penyebaran pandemi COVID-19. Langkah pertama adalah melakukan pertemuan daring tim PPDM untuk mendalami kebijakan Kemenristek/BRIN ini (Gambar 2). Kemudian menyiapkan pertemuan daring dengan manajemen KBG (di Dusun Grangsil), permasalahan muncul karena masyarakat belum pahan tentang online system. Sehingga perlu disusun panduan pertemuan daring (Gambar 3), yang digunakan untuk pedoman penggunaan daring (dilakukan komunikasi denga WA) antara tim PPDM dengan Mitra KBG.
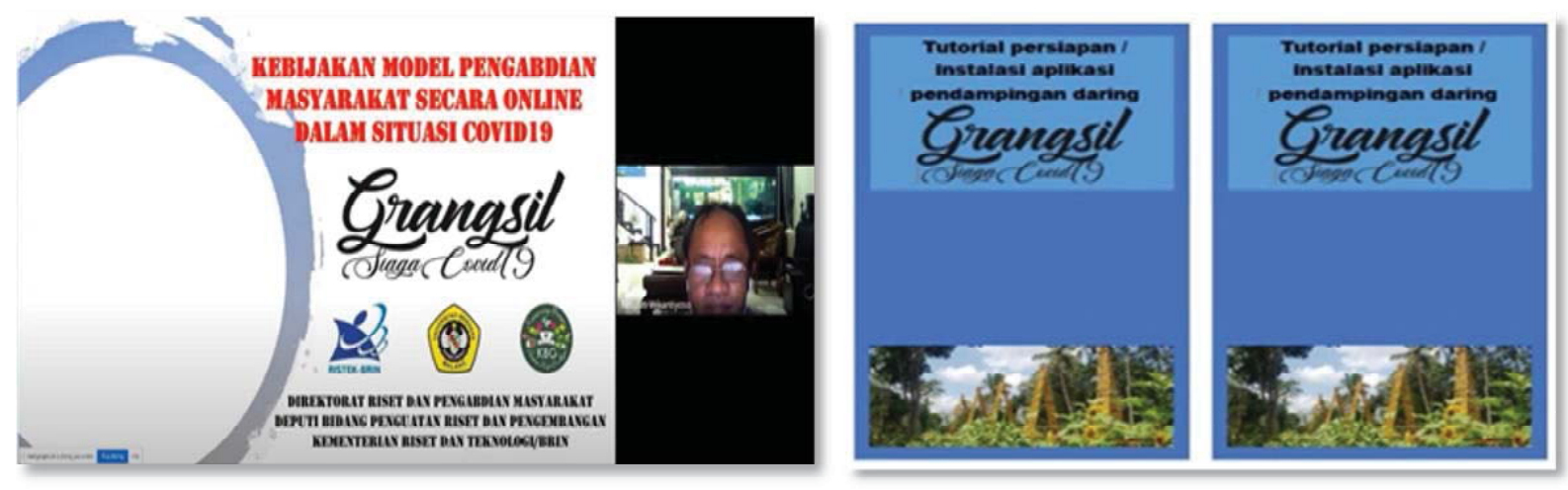

Gambar 3. Pertemuan daring tim PPDM kebijakan Kemenristek/BRIN

Gambar 4. Buku saku tutorial persiapan/instalasi aplikasi pendampingan daring

Langkah ini sangat efektif, walaupun dengan masyarakat di Dusun Grangsil ternyata mampu untuk menyerap isi dari panduan yang dibuat oleh TIM. Potensi masyarakat yang telah menggunakan HP Android, dapat dimanfaatkan melalui intervensi pemanfaatan IT untuk pertemuan daring. Dengan demikian kendala terhadap upaya-upaya pendampingan secara online dapat teratasi. Rapat daring tanggal 2 Mei 2020, direspon sangat antusias oleh mitra. Rapat daring persiapan pengurusan Badan Hukum Koperasi Boenga Grangsil secara daring, peserta pembina sekaligus anggota luar biasa Bapak Tugino S., SE., Kol. Purn. Badan pengawas Koperasi Boenga Grangsil, pengurus dan anggota koperasi dan Tim PPDM 2020 Unmer (Gambar 4). 


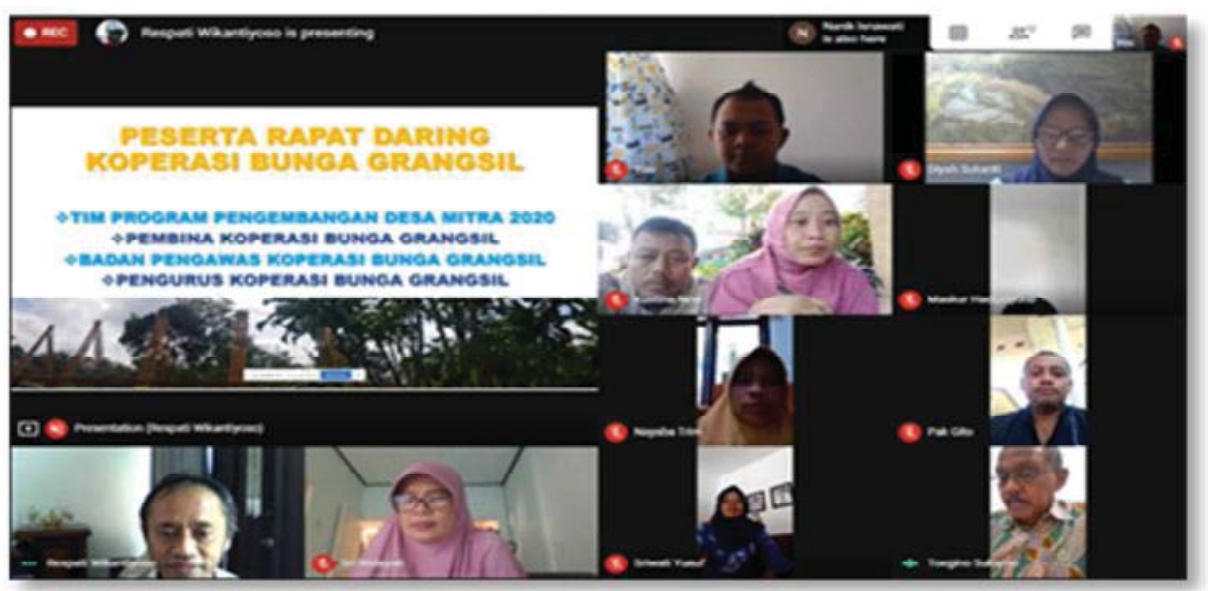

Gambar 5. Pertemuan daring pendampingan Koperasi Boenga Grangsil

Dalam rangka menjawab permasalahan tentang kemampuan mengatasi permasalahan pandemi COVID-19 secara kelembagaan perlu dilakukan beberapa kegiatan penguatan kelembagaan. Kegiatan ini bertujuan untuk menciptakan kondisi resilience destination management atau kondisi manajemen yang tangguh menghadapi COVID-19. Kemampuan secara kelembagaan untuk mengantisipasi, mencegah, dan mengatasi penyebaran pandemi COVID-19 menjadi prasyarat untuk menyusun protokol COVID-19. Peningkatan kemampuan ini dilakukan dengan pendampingan online, memberikan bantuan hibah untuk pelaksanaan protokol COVID-19. Bantuan hibah peralatan diantaranya: (1) Masker untuk masyarakat sebayak 250 buah (dari donatur), dan 200 buah masker untuk mendukung operasi tertib bermasker yang diselenggarakan tim satgas COVID-19; (2) 4 buah thermo gun untuk operasional harian pengunjung/ wisatawan; (3) Faceshield sebanyak 30 buah untuk Tim KBG dan satgas COVID-19; (4) Rompi satgas sebanyak 20 buah untuk tim satgas COVID-19; dan (5) Kaos seragam siaga COVID-19 sebanyak 30 buah untuk tim operasional KBG.

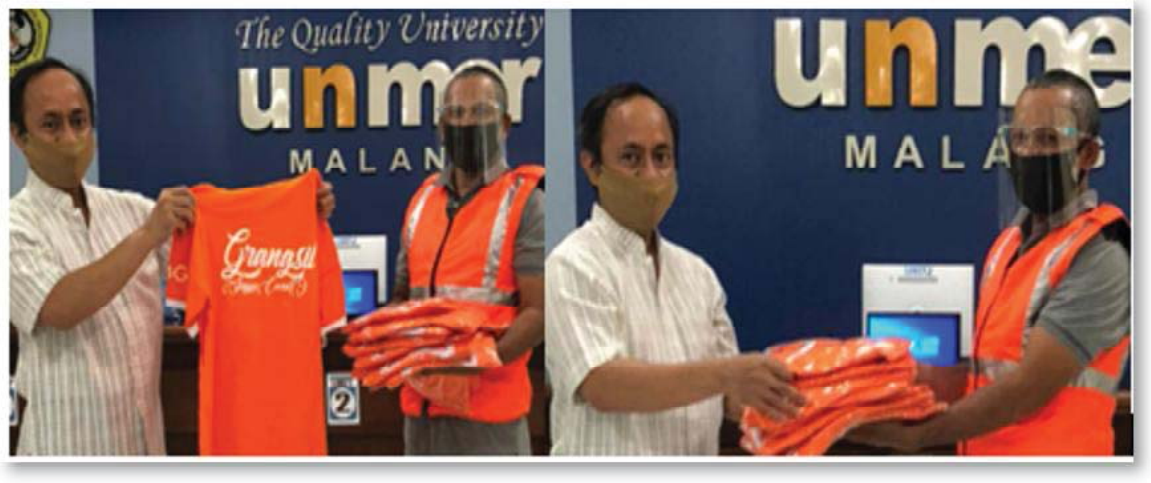

Gambar 6. Penyerahan peralatan pencegahan COVID-19 di Kampus Unmer Malang

Penyerahan dilakukan di Universitas Merdeka Malang, yang diwakili oleh Kepala Dusun Grangsil untuk mengurangi kontak sosial yang lebih banyak (Gambar 5). Selain itu tim PPDM ikut menyalurkan APD sebanyak 15 buah dari donatur untuk tim COVID-19 Desa Jambangan, dan POSYANDU Dusun Grangsil. 
ABDIMAS: Jurnal Pengabdian Masyarakat Universitas Merdeka Malang Volume 5, No 3, November 2020: 181-192

Tim PPDM2020 memandang penting untuk membentuk tim siaga COVID-19 di level KBG dan tim satuan tugas COVID-19 untuk level Dusun Grangsil dan Desa Jambangan yang bertugas sebagai tim penanggulangan penyebaran COVID-19 di Dusun Grangsil, khususnya di destinasi wisata Kampoeng Boenga Grangsil. Struktur organisasi tim penanggulangan penyebaran virus corona (COVID-19), disahkan oleh Kepala Desa Jambangan, Kecamatan Dampit, Kabupaten Malang. Pelibatan kepala desa dalam penyusunan dan pembuatan surat struktur organisasi satuan tugas COVID-19 oleh Kepala Desa Jambangan. Mitra diminta untuk memberikan informasi, serta selalu koordinasi dengan pemerintah desa dan tim. Pemerintah Desa Jambangan sangat mendukung untuk pembentukan tim siaga COVID-19 maupun satgas COVID-19. Kegiatan pertama tim penanggulangan penyebaran COVID-19 adalah operasi tertib masker, pada hari Sabtu 18 Juli 2020. Sarasan operasi adalah pengunjung KBG dan masyarakat sekitar KBG.

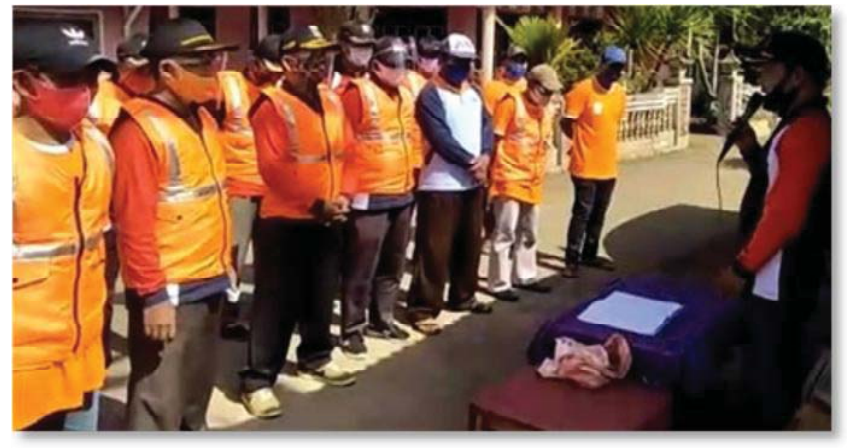

Gambar 7. Sambutan kepala Desa Jambangan dalam acara operasi tertib

Pembentukan satgas COVID-19 Kampoeng Boenga Grangsil, paling tidak dapat mencegah penyebaran COVID-19 ini. Upaya ini sangat penting untuk meningkatkan kesadaran, masyarakat, pengunjung, dan petugas wisata dalam melaksanakan dan mematuhi protokol kesehatan. Dalam upaya mencegah penularan COVID-19, Wisata Kampoeng Boenga Grangsil membentuk satgas COVID-19 dan mengadakan kegiatan disliplin masker di Kawasan Dusun Grangsil Desa Jambangan Kecamatan Dampit pada Sabtu 18 Juli 2020 bersama Muspika Dampit, Koramil, kecamatan, Babinsa, Puskesmas Dampit, kepala desa dan perangkat serta Tim KBG (Gambar 7). Kegiatan ini dilaksanakan agar warga dan pengunjung KBG disiplin dan mengenakan masker saat keluar rumah, serta mematuhi protokol kesehatan sesuai dengan ketetapan pemerintah. Pemberitaan terdapat pada https://bit.ly/ppdm2020disiplinmasker dan link Youtube https:// bit.ly/operasimasker.

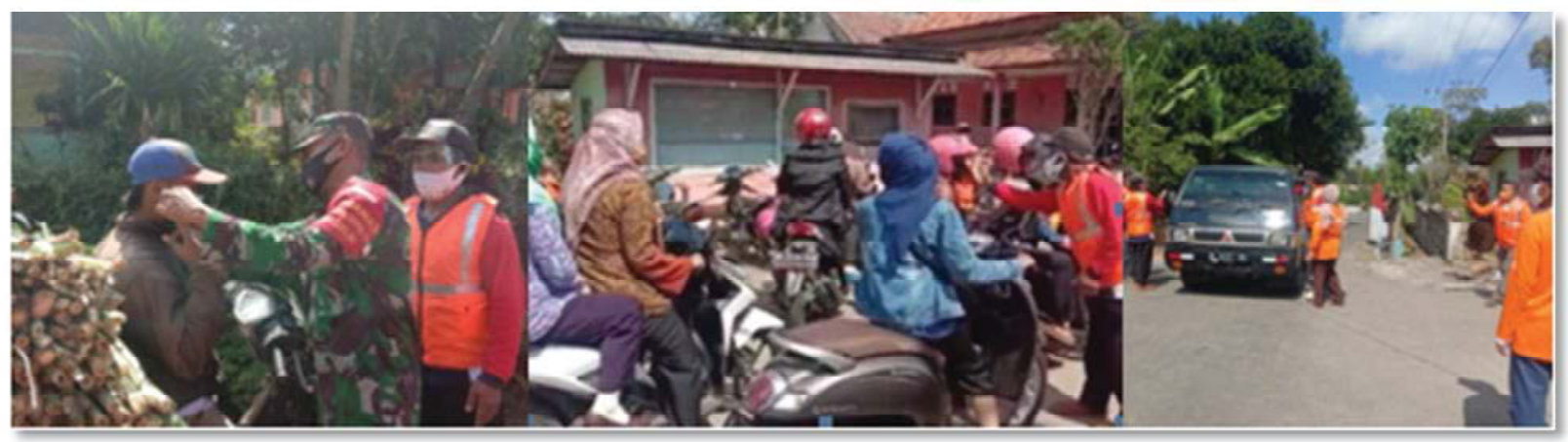

Gambar 8. Rangkaian kegiatan operasi tertib masker di KBG. 
Penyusunan protokol-protokol kesehatan terkait dengan menyongsong new normal order, untuk kelengkapan dan penyiapan fasilitas dan kegiatan-kegiatan menyongsong masa transisi menuju new normal order (Gambar 8 dan 9). Pelaksanaan diawali dengan kegiatan FGD, diskusi Tim PPDM2020 yang membahas tentang fasilitas serta kegiatan-kegiatan yang dimungkinkan masih bisa dilaksanakan pasca pandemi COVID-19 atau pada masa transisi menuju new normal. Penyusunan panduan pertemuan daring dan protokol-protokol kesehatan. Karena pandemi COVID-19, dengan adanya protokol social distancing, serta physical distancing, maka pelaksanaan pertemuan harus dilaksanakan secara daring. Khususnya untuk kegiatan rapat yang melibatkan Tim PPDM.
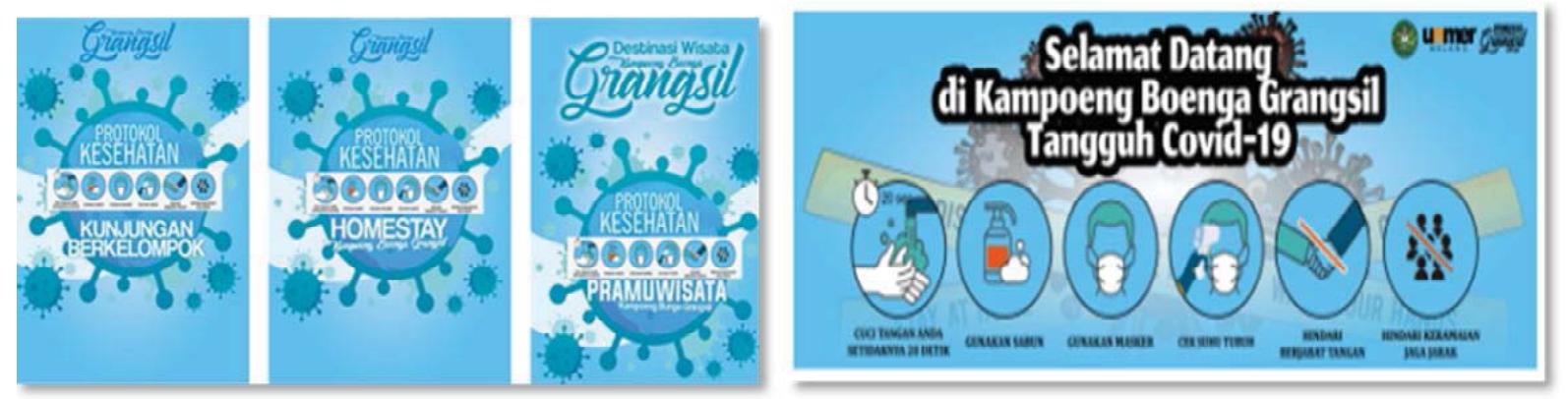

Gambar 9. Beberapa contoh protokol COVID-19

Gambar 10. Contoh standar peringatan penerapan Protokol COVID-19

Pelaksanaan PPDM 2020, selain menangani permasalahan krusial tentang pandemi COVID-19, juga tetap melaksanakan penanganan permasalahan terkait dengan upaya peningkatan pengetahuan dan kemampuan tata kelola, dan kelembagaan, dalam mewujudkan masyarakat yang mandiri, tangguh, dan berkelanjutan (sustainable resilience community). Tabel 1 memberikan abstraksi singkat tentang permasalahan penanganan pengembangan $\mathrm{KBG}$, beserta indikator pengukurannya.

Tabel 1. Permasalahan dan indikator pengembangan KBG

\begin{tabular}{|c|c|}
\hline Permasalahan & Indikator \\
\hline $\begin{array}{l}\text { Permasalahan utama yang menjadi tantangan terberat } \\
\text { dalam pengembangan KBG saat ini adalah penyebaran } \\
\text { pandemi COVID-19. Permasalahan ini tahun sebelumnya } \\
\text { tidak ada, keberadaan COVID-19 ini telah merubah } \\
\text { seluruh sendi kehidupan masyarakat. Sektor pariwisata } \\
\text { menjadi sektor yang paling terdampak oleh } \\
\text { permasalahan pandemi ini. }\end{array}$ & $\begin{array}{l}\text { - Kemampuan secara kelembagaan untuk mengantisipasi, } \\
\text { mencegah, dan mengatasi penyebaran pandemi COVID- } \\
19 \text { di Destinasi Wisata Kampoeng Boenga Grangsil } \\
\text { khususnya, dan Dusun Grangsil, Desa Jambangan Pada } \\
\text { Umumnya } \\
\text { - Terbentuknya satuan tugas COVID-19 dan Tim Siaga } \\
\text { COVID-19 Kampoeng Boenga Grangsil. } \\
\text { - Kesiapan operasionalisasi destinasi KBG pasca pandemi } \\
\text { COVID-19 dengan protokol new normal. }\end{array}$ \\
\hline $\begin{array}{l}\text { Permasalahan Pengembangan fisik obyek wisata; } \\
\text { Kegiatan ini banyak yang mengalami penyesuaian } \\
\text { karena kondisi pandemi COVID-19. Kegiatan } \\
\text { Pengembangan lebih ditekankan pada maintenance } \\
\text { Fasilitas dan penambahan fasilitas yang tidak menuntut } \\
\text { tatap muka yang intensif. Pendampingan in-situ lebih }\end{array}$ & $\begin{array}{l}\text { Kegiatan pendampingan penyusunan master plan dan detail } \\
\text { plan. Substansi pengembangan homestay dan beberapa } \\
\text { kegiatan ikutannya terpaksa ditiadakan pada tahun ini. } \\
\text { Secara komprehensif target pelaksanaan ditunda sampai } \\
\text { akhir tahun ketiga. Kegiatan substansial master plan } \\
\text { dialihkan untuk penanganan permasalahan pandemi }\end{array}$ \\
\hline
\end{tabular}

(melalui media WA dan Rapat Daring) 
ABDIMAS: Jurnal Pengabdian Masyarakat Universitas Merdeka Malang

Volume 5, No 3, November 2020: 181-192

Pendampingan disain/penambahan fasilitas:

- Fasilitas penunjang protokol COVID-19; tempat cuci tangan, dan penyediaan air bersih

- Pembuatan fasilitas "Kantor Koperasi Boenga Grangsil" di lokasi rumah pengurus (embrio kantor)

Pendampingan dan pembangunan (maintenance) fasilitas akses jalan dan Fasilitas lainnya.

Permasalahan pemanfaatan teknologi IT dan TTG; Pemanfaatan media berbasis IT menjadi sangat penting untuk menyebarkan informasi tentang keberadaan KBG, serta prasyarat dalam melakukan kunjungan di KBG sesuai Protokol COVID-19. Media website, FB dan IG menjadi media yang dikembangkan dalam mengatasi permasalahan pemasaran KBG.

Permasalahan pemberdayaan kegiatan pengelolaan organisasi masyarakat dalam

dalam $\mathrm{Pe}$

Pengembangan website Kampoeng Boenga Grangsil, dengan melakukan update berita yang dilakukan oleh admin (Tim KBG). Indikator kegiatan ini adalah terupdatenya website KBG, dan persiapan pembuatan website Koperasi Boenga Grangsil.
Peningkatan pengetahuan dan kemampuan menuju
kemandirian, dan masyarakat yang tangguh (community
resilience)

Peningkatan pengetahuan dan kemampuan tata kelola, dan kelembagaan, dalam mewujudkan masyarakat yang mandiri, tangguh, dan berkelanjutan (Sustainable resilience community).

Penguatan kelembagaan Kampoeng Boenga Grangsil, dilakukan melalui pembentukan Koperasi Boenga Grangsil. Koperasi Boenga Grangsil menjadi payung semua aktivitas pengembangan kegiatan usaha produktif di Dusun Grangsil.

\section{SIMPULAN DAN SARAN}

\section{Simpulan}

Tim PPDM sebagai representasi institusi perguruan tinggi, bertindak sebagai mediator dan fasilitator dalam pengembangan KBG, melalui pendampingan in-situ dan ex-situ untuk memberi penguatan dan pemberdayaan menuju komunitas tangguh (resilience community) dan mandiri dalam mengembangkan potensi lokalnya. Peran dan keterlibatan dalam proses pembangunan partisipatif bertujuan untuk mengingkatkan kemampuan masyarakat, mengorganisir diri membangun desa secara berkelanjutan. Pengembangan KBG menjadi destinasi wisata berbasis masyarakat berkelanjutan membutuhkan keterlibatan 3 pihak, yaitu: (1) Tim PPDM (perguruan tinggi); (2) Organisasi kemasyarakatan Dusun Grangsil; (3) Lembaga eksternal, pemerintah daerah, dan lembaga swasta.

\section{Saran}

Pandemi COVID19 telah mengubah kondisi "kenormalan" di semua sektor kehidupan. Pengembangan pariwisata berbasis masyarakat melalui pemberdayaan modal sosial masyarakat memiliki tantangan signifikan dalam menghadapi penguatan dan ketahanan sektor pariwisata pasca pandemi COVID-19. Ketidakpastian berakhirnya pandemi COVID-19, mengharuskan kita untuk mampu beradaptasi dengan kondisi baru, prasyarat baru (social and physical distancing), protokol baru, tatanan baru (fisik, social dan kesehatan), dengan mempersiapkan protokol tatanan kenormalan baru (new normal order). Destinasi wisata harus mampu mengadaptasi new normal order untuk survive di masa mendatang. Masyarakat 
yang tangguh (resilience community) akan dengan mudah melakukan hal tersebut karena kemampuan dan kemauan untuk meningkatkan ketahanan komunitas sudah menjadi kemampuan bawah sadar mereka.

\section{UCAPAN TERIMA KASIH}

Kami mengucapkan terima kasih kepada masyarakat Dusun Grangsil, Desa Jambangan, Kecamatan Dampit, Kabupaten Malang atas waktu dan partisipasinya dalam penelitian ini. Khususnya kepada mitra Kampoeng Boenga Grangsil atas kerja keras, komitmen, dan semangat dalam mewujudkan impiannya menjadikan KBG sebagai penggerak ekonomi keluarga, dan masyarakat Dusun Grangsil pada umumnya. Pengabdian ini didanai oleh Direktorat Penelitian dan Pengabdian kepada Masyarakat, Direktorat Jenderal Penguatan Penelitian dan Pengabdian kepada Masyarakat; Kementerian Riset, Teknologi, dan Pendidikan Tinggi melalui Kontrak Pengabdian kepada Masyarakat Nomor: 111 / SP2H / PPM / DRPM / 2019. Program Desa Mitra merupakan kegiatan Pengabdian kepada Masyarakat multi tahun dari tahun 2019 sampai dengan 2021. Temuan dan kesimpulan ini bermanfaat bagi pengembangan KBG sebagai destinasi wisata berbasis komunitas berkelanjutan. Terima kasih kembali kepada seluruh pemangku kepentingan yang telah meluangkan waktu dan dukungannya kepada pengabdi.

\section{DAFTAR PUSTAKA}

Adger, W. N. (2000). Social and ecological resilience: Are they related? Progress in Human Geography, 24(3), 347-364. https://doi.org/10.1191/030913200701540465

Aleksandrov, K., \& Kilimperov, I. (2018). The role of destination management organizations (DMOS) for sustainable rural tourism in Bulgaria. Scientific Papers Series Management, Economic Engineering in Agriculture and Rural Development, 18(2), 11-160.

Amir, S., Osman, M. M., Bachok, S., \& Ibrahim, M. (2015). Sustaining local community economy through tourism: Melaka UNESCO World Heritage City. Procedia Environmental Sciences, 28, 443-452. https://doi.org/10.1016/j.proenv.2015.07.054

Andriany, D., Hasibuan, L. S., \& Rahayu, S. E. (2018). Pengembangan model pendekatan partisipatif dalam memberdayakan masyarakat miskin kota Medan untuk memperbaiki taraf hidup. Kumpulan Penelitian dan Pengabdian Dosen, 1(1).

Astuti, S. I. (2001). Pendekatan partisipatif lewat pemberdayaan rakyat: Alternatif bagi pembangunan berwawasan otonomi daerah. Mimbar: Jurnal Sosial dan Pembangunan, 17(2), 212-237.

Begum, H., Er, A. C., Alam, A. F., \& Sahazali, N. (2014). Tourist's perceptions towards the role of stakeholders in sustainable tourism. Procedia-Social and Behavioral Sciences, 144, 313-321. https://doi.org/10.1016/j.sbspro.2014.07.301

Caldito, L. A., Dimanche, F., Vapnyarskaya, O., \& Kharitonova, T. (2015). Tourism Management. Tourism in Russia: A Management Handbook, 57-99.

CARRI. (2014). Definition of Community Resilience; An Analysis Definition of Community Resilience. CARRI: Community \& Regional Resilience Institute.

Mujanah, S., Ratnawati, T., \& Andayani, S. (2016). Strategi pengembangan desa wisata di kawasan hinterland Gunung Bromo Jawa Timur. JHP17: Jurnal Hasil Penelitian, 1(1), 33-52. 
ABDIMAS: Jurnal Pengabdian Masyarakat Universitas Merdeka Malang

Volume 5, No 3, November 2020: 181-192

Mulyani, S. (2017). Buku Pintar Dana Desa, Dana Desa untuk Kesejahteraan Rakyat. Kementrian Keuangan Republik Indonesia. Jakarta. https://www.kemenkeu.go.id

Pamatang, C., Sianipar, M., \& Yudoko, G. (2013). Community empowerment through appropriate technology/: Sustaining the sustainable development. Procedia Environmental Sciences, 17, 1007-1016. https://doi.org/10.1016/j.proenv.2013.02.120

Sharifi, A. (2016). A critical review of selected tools for assessing community resilience. Ecological Indicators, 69, 629-647. https://doi.org/10.1016/j.ecolind.2016.05.023

Shaw, T. (1993). Planning for A sustainable environment. A report by the town and country planning association. Edited by Andrew Blowers Earthscan, London. Business Strategy and the Environment, 2(4), 38-39. https://doi.org/10.1002/bse.3280020407

Siri, R., \& Chantraprayoon, O. S. (2017). Local community participatory learning with a nature interpretation system: A case study in Ban Pong, Sansai district, Chiang Mai, Thailand. Kasetsart Journal of Social Sciences, 38(2), 181-185. https://doi.org/10.1016/j.kjss.2016.04.003

Sudirah. (2015). Modal sosial dan pemberdayaan masyarakat desa wisata. Prosiding Seminar Nasional Fakultas Ilmu Sosial dan Ilmu Politik, Universitas Terbuka UTCC, 26 Agustus 2015, (2001), 148156.

Wikantiyoso, R., Sukanti, D., Sulaksono, A. G., \& Widayati, S. (2019). Empowerment and strengthening of community resilience in developing ecotourism destination in Grangsil Hamlet, Malang Regency, Indonesia. Conference: 3rd Endinamosis 2019 International Conference on "Empowering Rural Areas in the Industry 4.0 Era," 11. Bandung: ITB.

WWF-Indonesia. (2009). Prinsip dan kriteria ekowisata berbasis masyarakat. Ekowisata, 1-9. 